\title{
Avaliação da atividade laxante de Operculina macrocarpa L. Urban (Convolvulaceae)
}

\author{
Michelin, D. C.; Salgado, H. R. N. \\ Programa de Pós-Graduação em Ciências Farmacêuticas, Faculdade de Ciências Farmacêuticas, \\ Universidade Estadual Júlio Mesquita Filho, Araraquara, SP.
}

Recebido para publicação em: 20/112003 Aceito para publicação em: 30/04/2004

\begin{abstract}
RESUMO: O objetivo deste trabalho foi avaliar os efeitos sobre a motilidade intestinal de Operculina macrocarpa L. Urban, popularmente conhecida como batata-de-purga ou jalapa, nativa do nordeste brasileiro, que é indiscriminadamente utilizada pela população como laxante. O extrato hidroetanólico e suas frações diclorometano, acetato de etila, $n$-butanol e final foram avaliados quanto a sua atividade laxante, através do teste da motilidade intestinal em camundongos, assim como de uma preparação com o pó da planta, como é utilizada pela população. Os resultados mostraram que as frações diclorometano, acetato de etila, final e o pó da planta possuem efeito laxante no modelo experimental adotado.
\end{abstract}

Unitermos: Operculina macrocarpa; Convolvulaceae; in vivo; motilidade intestinal.

\begin{abstract}
Evaluation of the laxative activity of Operculina macrocarpa L. Urban (Convolvulaceae). The aim of this work was to evaluate the effects on mice intestinal motility after oral administration of Operculina macrocarpa L. Urban, known as "batata-depurga" or "jalapa", a northeast Brazilian medicinal plant used as a laxative. An hydroalcoholic decoction and dichloromethane, ethyl acetate, n-buthanol and residual fractions, as well as the powder preparation of "batata de purga" - as it is traditionally used - were evaluated. The results showed that dichloromethane, ethyl acetate and residual fractions, and the powder preparation showed a significant increase of the intestinal motility, in our experimental conditions.
\end{abstract}

KEYWORDS: Operculina macrocarpa; Convolvulaceae; in vivo; intestinal motility.

\section{INTRODUÇÃO}

Operculina macrocarpa L. Urban (Convolvulaceae) popularmente conhecida como batatade-purga ou jalapa, é comum no nordeste brasileiro, e apresenta raízes tuberosas, grandes, amiláceas e resiníferas. É uma trepadeira de aspecto ornamental, especialmente pelos seus 
frutos. Cada fruto contém uma a quatro sementes duras e pretas. Esta espécie é bienal, tem flor branca e frutos arredondados (MATOS, 1994).

O. macrocarpa é uma espécie silvestre, mas pode ser facilmente cultivada pelo plantio das sementes ou mesmo dos tubérculos. Esses, quando adultos, são arrancados, cortados transversalmente em fatias estreitas, postas a secar ao sol, sendo comercializadas sob o nome de aparas de batata (MATOS, 1994).

A batata-de-purga é amplamente utilizada pela população devido à sua atividade laxante, purgativa, depurativa contra moléstias da pele e no tratamento da leucorréia. Para este fim, emprega-se a decocção do tubérculo seco (MARTINS et al., 2000; MATOS, 1982).

Uma das características mais marcantes das convolvuláceas é a presença de fileiras de células secretoras de resinas glicosídicas em tecidos foliares e, especialmente, em suas raízes. Estas substâncias constituem uma das características quimiotaxonômicas desta família, e o emprego na medicina tradicional de plantas de alguns gêneros (Convolvulus, Exogonium, Ipomoea, Merremia e Operculina) está associado às propriedades purgantes de suas resinas (GARCIA-ARGÁEZ; PÉREZ-AMADOR, 1997; PÉREZ-AMADOR et al., 1998; PEREDA-MIRANDA et al., 2003). Entretanto pouco ainda é mencionado sobre o mecanismo da ação laxante relacionada às resinas glicosídicas (PEREDA-MIRANDA; BAH, 2003).

Tendo em vista a comercialização e a utilização de amostras pulverizadas de $O$. macrocarpa para o tratamento da constipação intestinal e, considerando que existem poucos estudos na literatura com o referido vegetal, este trabalho teve como objetivo avaliar o efeito desta planta sobre o trânsito intestinal de camundongos.

\section{MATERIAIS E MÉTODOS}

\section{Preparação dos extratos}

O pó da planta foi adquirido comercialmente, acompanhado do laudo do fornecedor, tendo sido identificado pelo farmacêutico Georges F. Nabahan (CRF 10.994). Os testes descritos na monografia da planta (FARMACOPÉIA BRASILEIRA, 1959) foram realizados e confirmaram a identidade da amostra.

O extrato etanólico (EE-BR) foi preparado com $50 \mathrm{~g}$ do pó da planta, que foram extraídos por decocção, sob refluxo, durante $30 \mathrm{~min}$, com $500 \mathrm{~mL}$ de etanol $70 \%$. Este processo extrativo foi repetido por três vezes. Os decoctos hidroetanólicos foram reunidos e concentrados até 500 $\mathrm{mL}$. Desses, $100 \mathrm{~mL}$ foram levados à secura em evaporador rotatório para obtenção do extrato bruto, denominado EE-BR. Os $400 \mathrm{~mL}$ restantes foram submetidos à partição líquido-líquido com $200 \mathrm{~mL}$ de solventes de polaridade crescente: diclorometano, acetato de etila e $n$-butanol, obtendo-se as frações EE-FD, EE-FE e EE-FB, respectivamente. A fração etanólica final foi denominada EE-FF. Esse procedimento foi repetido três vezes, e após o fracionamento, os solventes utilizados foram evaporados.

\section{Teste da motilidade intestinal em camundongos}

No ensaio de trânsito intestinal foram utilizados os materiais-teste: EE-BR, EE-FD, EEFE, EE-FB, EE-FF e, ainda, o pó da batata de purga, todos ressuspendidos em solução fisiológica a $50 \mathrm{mg} / \mathrm{mL}$, ou solução fisiológica acrescida de gotas de polissorbato 80 para aquelas frações insolúveis (EE-FD, EE-FE,EE-FB).

Foram utilizados camundongos Swiss (Mus musculus), machos, com 30 dias de idade, pesando entre 22 e $30 \mathrm{~g}$, os quais foram adaptados ao biotério experimental, durante cinco dias, 
antes do início dos ensaios biológicos. Os animais, mantidos em livre acesso à alimentação e água, ficaram em ambiente com temperatura de $20 \pm 1^{\circ} \mathrm{C}$, umidade monitorada e fotoperíodo de 12 horas claro/escuro. No dia do experimento, os animais foram mantidos em jejum por $3 \mathrm{~h}$ e receberam água ad libitum.

Foram constituídos seis grupos experimentais com 10 animais cada, que foram tratados com os materiais-teste: (EE-BR, EE-FD, EE-FB, EE-FE, EE-FF e pó), na dose de $1000 \mathrm{mg} / \mathrm{kg}$; dois outros grupos experimentais foram tratados com os materiais-teste EE-FD e EE-FE, em menor dose $(100 \mathrm{mg} / \mathrm{mL})$ e dois grupos controle, um que recebeu solução fisiológica $(10 \mathrm{~mL} / \mathrm{kg})$, e outro que recebeu solução fisiológica acrescida de gotas de polissorbato 80 (10 mL/kg). Todos os tratamentos foram por via oral, através de agulha de gavage.

Após 45 min, os animais receberam a suspensão de carvão ativo 10\% em solução de goma arábica $5 \%(0,3 \mathrm{~mL} /$ animal) também via oral, através de agulha de gavage.

Após 45 min, os camundongos foram sacrificados em câmara de $\mathrm{CO}_{2}$ e foi realizada a extirpação imediata do intestino desde o piloro até o início do ceco. Assim, foi feita a medida do comprimento total do intestino delgado e da distância percorrida pela suspensão de carvão ativo. O resultado foi expresso em porcentagem do comprimento total do intestino delgado. Os intestinos foram pesados individualmente em balança analítica.

A atividade sobre o trânsito intestinal foi determinada segundo Janssen e Jageneau (1957) e Wong e Wai (1981).

Esta pesquisa foi aprovada pelo Comitê de Ética em Pesquisa da Faculdade de Ciências Farmacêuticas da Unesp - Araraquara, através do parecer no 12/2003.

\section{Análise estatística}

Os resultados experimentais foram expressos em média \pm desvio padrão. A análise estatística foi realizada pelo Teste-t de Student $(P<0,05)(D E M U T H, 1999)$.

\section{RESULTADOS E DISCUSSÃO}

As quantidades obtidas dos materiais-teste foram: EE-BR 2,4 g; EE-FD 3,9 g; EE-FE 2,1 g; EE-FB 1,2 g e EE-FF 4,5 g.

Os resultados obtidos no ensaio demonstraram um aumento significativo da motilidade intestinal (Tabelas 1 e 2).

Tabela 1. Distâncias percorridas pelo carvão ativo no intestino de camundongos, sob a influência de diferentes tratamentos.

\begin{tabular}{l|c|c|}
\hline \multicolumn{1}{|c|}{ Tratamento } & $\begin{array}{c}\text { Dose } \\
\text { (mg/kg de peso animal) }\end{array}$ & $\begin{array}{c}\text { Distância percorrida pelo carvão ativo } \\
(\%) \pm \text { desvio padrão }\end{array}$ \\
\hline Controle 1 & $10 \mathrm{~mL} / \mathrm{kg}$ & $47,82 \pm 34,68$ \\
EE-BR & $1 \mathrm{~g} / \mathrm{kg}$ & $69,99 \pm 16,83$ \\
EE-FF & $1 \mathrm{~g} / \mathrm{kg}$ & $90,32 \pm 9,71^{*}$ \\
PÓ & $1 \mathrm{~g} / \mathrm{kg}$ & $88,58 \pm 17,75^{\star}$ \\
\hline
\end{tabular}

Controle 1: solução fisiológica; $n=10 ; \%=$ média dos 10 animais; * $p<0,05$. 
Tabela 2. Distâncias percorridas pelo carvão ativo no intestino de camundongos, sob a influência de diferentes tratamentos.

\begin{tabular}{l|c|c|}
\hline \multicolumn{1}{|c|}{ Tratamento } & $\begin{array}{c}\text { Dose } \\
\text { (mg/kg de peso animal) }\end{array}$ & $\begin{array}{c}\text { Distância percorrida pelo carvão ativo (\%) } \\
\pm \text { desvio padrão }\end{array}$ \\
\hline Controle 2 & $10 \mathrm{~mL} / \mathrm{kg}$ & $52,79 \pm 30,39$ \\
EE-FD & $1 \mathrm{~g} / \mathrm{kg}$ & $66,74 \pm 25,67$ \\
EE-FD & $100 \mathrm{mg} / \mathrm{kg}$ & $80,41 \pm 11,64$ * \\
EE-FE & $1 \mathrm{~g} / \mathrm{kg}$ & $64,72 \pm 20,48$ \\
EE-FE & $100 \mathrm{mg} / \mathrm{kg}$ & $85,42 \pm 9,85$ * \\
EE-FB & $1 \mathrm{~g} / \mathrm{kg}$ & $89,53 \pm 7,61^{*}$ \\
\hline
\end{tabular}

Controle 2: solução fisiológica + polissorbato 80; $n=10 ; \%=$ média dos 10 animais; * $p<0,05$.

Os tratamentos com EE-FB, EE-FF e com o pó de O. macrocarpa mostraram um aumento significativo na motilidade intestinal dos camundongos na dose de $1 \mathrm{~g} / \mathrm{kg}$, já as frações diclorometano (EE-FD) e acetato de etila (EE-FC) apresentaram resultado significativo numa dose menor (100 mg/kg), e não apresentaram o mesmo resultado na dose maior.

Tal fato pode ter ocorrido devido à uma diarréia causada pela alta dose dos extratos, e, conseqüentemente, na eliminação rápida do marcador, impossibilitando a medida real da distância percorrida pelo mesmo, uma vez que foi observada a presença de fezes líquidas, em um curto espaço de tempo.

Em conclusão, o efeito laxante de $O$. macrocarpa pode ser associado ao seu efeito propulsor da motilidade intestinal. Os resultados mostram que a batata-de-purga possui efeito laxante neste modelo experimental, comprovando seu uso etnomedicinal. Entretanto, estudos fitoquímicos são necessários para identificação da(s) substância(s) ativa(s) e, também, estudos farmacológicos para elucidar o seu exato mecanismo de ação.

\section{AGRADECIMENTOS}

Ao CNPq e ao PADC-FCF-UNESP.

\section{REFERÊNCIAS}

FARMACOPÉIA BRASILEIRA. 2.ed. São Paulo: Siqueira, 1959, p.542-543.

GARCIA-ARGÁEZ, A.; PÉREZ-AMADOR, M.C. Distribution in the plant of glycoresins and ergoline alkaloids in three species of Ipomoea (Convolvulaceae). International Journal of Experimental Botany, v.60, n.1-2, p.73-76, 1997.

JANSEN, P.; JAGENAU, A. H. A new series of potent analgesics. Part I - Chemical structure and pharmacological activity. Journal of Pharmacy and Pharmacology, v.9, p.381-400, 1957.

MARTINS, E. R.; CASTRO, D.M.; CASTELLANI, D.C.; DIAS, J.E. Plantas medicinais. Viçosa: UFV, 2000. MATOS, F.J.A. Aproveitamento de plantas medicinais da região nordeste. Revista Brasileira de Farmácia, v.63, n.3/4, p.132-140, 1982.

Rev. Bras. Farmacogn., V. 14, n. 2, jul.-dez. 2004. 
MATOS, F. J. A. Farmácias vivas. 2.ed. Fortaleza: EUFC, 1994.

PEREDA-MIRANDA, R.; TAKETA, A.T.C.; VILLATORO-VERA, R.A. Alucinógenos naturais: etnobotânica e psicofarmacologia. In: SIMÕES C.M.O.; SCHENKEL E.P.; GOSMANN G.; MELLO J.C.P.; MENTZ L.A.; PETROVICK P.R. Farmacognosia: da planta ao medicamento. 5.ed. Florianópolis: Editora da UFSC, cap.36, p.919-958, 2003.

PEREDA-MIRANDA, R.; BAH, M. Biodynamic constituents in the Mexican morning glories: purgative remedies transcending boundaries. Current Topics in Medicinal Chemistry, v.3, n.2, p.111-131, 2003.

PÉREZ-AMAdOR, M.C.; GARCíA-ARGÁEZ, A.; CONTRERAS, C.; HERRERA, J.; RíOS, M. Resins of four species of Convolvulaceae and their allelopatic potencial. International Journal of Experimental Botany, v.62, n.1/2, p.195-198, 1998.

WONG, C. L.; WAY, M. K. Effects of aspirin and paracetamol on naloxone reversal or morphine-induced inhibition of gastrointestinal propulsion in mice. European Journal of Pharmacology, v.73, p. 11-19, 1981.

\author{
* Autor para correspondência: \\ Profa. Dra. Hérida Regina Nunes Salgado \\ Departamento de Fármacos e Medicamentos \\ Faculdade de Ciências Farmacêuticas \\ Universidade Estadual Paulista \\ Rod. Araraquara-Jaú, Km 1 \\ 14801-902 - Araraquara - SP \\ E-mail: salgadoh@fcfar.unesp.br
}

